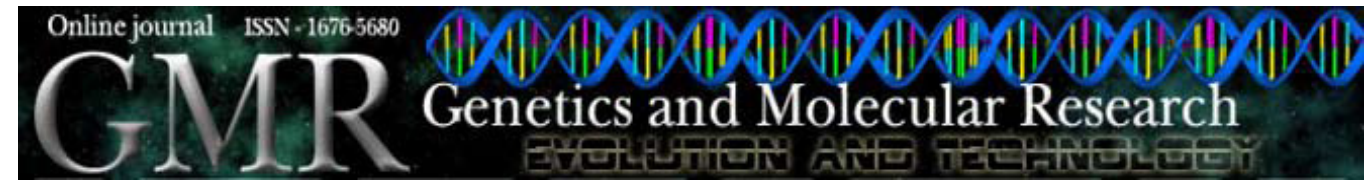

\title{
Genetic parameters for postweaning traits in Braunvieh cattle
}

\author{
D.C. Cucco ${ }^{1}$, J.B.S. Ferraz ${ }^{1}$, J.P. Eler ${ }^{1}$, J.C.C. Balieiro ${ }^{1}$, E.C. Mattos $^{1}$ and \\ L. Varona ${ }^{2}$ \\ ${ }^{1}$ Departamento de Ciências Básicas, \\ Grupo de Melhoramento Animal e Biotecnologia, \\ Faculdade de Zootecnia e Engenharia de Alimentos, \\ Universidade de São Paulo, Pirassununga, SP, Brasil \\ ${ }^{2}$ Departamento de Anatomía, Embriologia e Genética Animal, \\ Facultad de Veterinaria, Universidad de Zaragoza, Zaragoza, España \\ Corresponding author: D.C. Cucco \\ E-mail: diegocucco@yahoo.com.br
}

Genet. Mol. Res. 9 (1): 545-553 (2010)

Received December 11, 2009

Accepted January 12, 2010

Published March 23, 2010

\begin{abstract}
Genetic parameters for traits related to postweaning growth in Braunvieh cattle, reared under tropical and sub-tropical conditions in Brazil, were studied. Weight traits were weight at 365 days of age (W365, $\mathrm{N}=4055)$, at 450 days (W450, $\mathrm{N}=3453$ ), and at 550 days (W550, $\mathrm{N}=1946$ ), while weight gains were gain from weaning to 365 days of age (WGW365, $\mathrm{N}=3060$ ), from weaning to 450 days (WGW450, $\mathrm{N}=2764$ ), from weaning to 550 days (WGW550, $\mathrm{N}=1531$ ), from 365 to 550 days of age (WG365550, $\mathrm{N}=1528$ ), from 365 to 450 days (WG365450, $\mathrm{N}=2401$ ), and from 450 to 550 days (WG450550, $\mathrm{N}=1563$ ). A full animal model was used for estimating the variance components, using the MTDFREML software. The dataset contained 18,688 animals with phenotypic measures and 35,188 animals in the relationship matrix. Heritability estimates for postweaning weights decreased with age. For W365, W450 and W550, respectively, the direct heritability estimates were $0.29 \pm 0.061,0.25 \pm 0.057,0.16 \pm 0.060$, maternal heritability was $0.20 \pm 0.035,0.18 \pm 0.035,0.13 \pm 0.052$, and total
\end{abstract}


heritability was $0.30,0.35,0.26$. In this breed, maternal influence was found to be important up to 550 days of age. The greater genetic correlations between weights were observed for weights measured at shorter intervals. A large environmental effect was observed for weight gain between weaning and 550 days; this effect was greater for the gains between 365 and 550 days.

Key words: Beef cattle; Genetic and phenotypic correlations; Heritability; Maternal effect; Swiss cattle; Weight gain

\section{INTRODUCTION}

In beef cattle production, a large part of the revenues comes from the sale of animals after weaning. Thus, the maximization of animal development in this phase is interesting for breeders. With the aim of rapid and efficient growth, traits such as weight and weight gains after weaning can be measured and analyzed to determine their genetic parameters and to identify superior animals that may be selected and mated to produce the next generations.

In genetic evaluation of beef cattle, the postweaning period is very important. According to Cardoso et al. (2004), this period corresponds to a phase close to the final product and is the best representation of the environment where animals are raised, where it is not directly influenced by maternal effects.

The measure of weights is traditional and usually utilized to determine the animal's development. Through this procedure, weight gains can be calculated in predetermined periods, in order to determine the growth potential of the animal. Thus, weight gains are important traits and should be included in breeding programs. In Brazil, the first weight measurement after weaning generally occurs at around 12 months of age, or 365 days (W365). In this phase, the animal has a high growth potential. Other weights that can be measured are at 450 days (W450) and 550 days of age (W550). W550 is generally the last weight measured, because, normally, animals are not sold after this age. At 550 days of age, the animals start the reproductive phase of their lives, or they are finished and ready to be slaughtered.

Some breeding programs are adopting a new selection criterion for the evaluation of cattle, i.e., postweaning growth (Bittencourt et al., 2002), changing the age of measurement of postweaning growth from 550 to 450 days of age, with the aim of decreasing the generation interval and maximizing the genetic gain. The reduction in the age of measurement and the number of measurements according to Siqueira et al. (2003) is of great importance, because it allows the breeders to anticipate the sale of their animals and to select heifers for mating at earlier ages.

The knowledge of genetic parameters such as heritability coefficients and genetic correlations is necessary to conduct efficient breeding programs (Corrêa et al., 2006). This knowledge is of fundamental importance in the determination of selection methods and in the prediction of genetic gains for the studied population (Cardoso et al., 2004).

The first studies made with a population of Braunvieh breed under Brazilian conditions were reported by Cucco (2008) and Cucco et al. (2009). Given the importance of postweaning development, this study aimed to estimate the genetic parameters for weights and weight gains, and their genetic correlations in Braunvieh cattle reared in Brazil. 


\section{MATERIAL AND METHODS}

The dataset used came from the Nucleus of Braunvieh Breeders of Brazilian Breeders Association of Braunvieh and Brown Swiss Cattle - ABCGPS (http://www.pardo-suico.com. br/). Databank and genetic evaluation analysis are carried out by the Animal Breeding and Biotechnology Group of the College of Animal Science and Food Engineering, University of São Paulo, Brazil (GMAB - FZEA/USP).

The databank contained records from 28 farms located in Mato Grosso do Sul, Paraná, Santa Catarina, and São Paulo States, latitude S $23^{\circ} \pm 5^{\circ}$, longitude E $50^{\circ} \pm 5^{\circ}$, for a total of 18,688 animals with records and 35,188 animals on pedigree (369 sires and 12,284 dams).

Traits analyzed were W365, W450 and W550, and weight gains from weaning to 365 days of age (WGW365), from weaning to 450 days (WGW450) and from weaning to 550 days (WGW550), weight gains from 365 to 450 days of age (WG365450), from 365 to 550 days (WG365550) and from 450 to 550 days (WG450550). The criteria for the standardization of weights and weight gains are described in the study of Cucco (2008). The descriptive statistics of all traits are given in Table 1.

Table 1. Descriptive statistics for weight and weight gains.
\begin{tabular}{lccccc}
\hline Traits & Number of records & Number of CG & Mean & Coefficient of variation (\%) & Standard deviation \\
\hline W365 & 4055 & 406 & 312.40 & $20.07 \%$ & 62.71 \\
W450 & 3453 & 366 & 372.85 & $21.14 \%$ & 78.82 \\
W550 & 1946 & 300 & 408.58 & $20.76 \%$ & 84.82 \\
WGW365 & 3060 & 352 & 96.09 & $50.43 \%$ & 48.45 \\
WGW450 & 2764 & 324 & 152.60 & $41.74 \%$ & 72.70 \\
WGW550 & 1531 & 264 & 192.15 & $37.55 \%$ & 49.14 \\
WG365550 & 1528 & 262 & 97.14 & $50.59 \%$ & 27.74 \\
WG365450 & 2401 & 325 & 51.13 & $54.25 \%$ & $63.77 \%$ \\
WG450550 & 1563 & 260 & 51.29 & 32.71 \\
\hline
\end{tabular}

Traits were measured in kg; $\mathrm{CG}=$ number of contemporary groups; W365 = weight at 365 days of age; W450= weight at 450 days of age; W550 = weight at 550 days of age; WGW365, WGW450, WGW550 = weight gain from weaning to $365,450,550$ days of age, respectively. WG365550, WG365450, WG450550 = weight gains from 365 to 550 days, from 365 to 450 days and from 450 to 550 days, respectively.

The establishment of fixed effects and covariates as well as the elimination of outliers was conducted in the same way as that published by Cucco et al. (2009). The effects considered as fixed were contemporary group, class of age of the dam at calving, and breeding type (embryo transfer or not). The covariates used were direct and maternal heterozygosity and age of animal at measurement. The effects considered as random were direct additive genetic, maternal additive genetic and residual effects. A full animal model was used to estimate genetic parameters. The maternal effect was not considered for the weight gain between 365 and 550 days of age. Single and two-trait analyses were carried out using MTDFREML - multiple trait derivative free restricted maximum likelihood (Boldman et al., 1995). The convergence criterion was simplex variance of $10^{-9}$. Several reboots were performed with parameters estimated in the previous round until no change was observed in the last decimal of the $\log -2 \lambda$ for two consecutive reboots. The general mathematical model used was:

$$
y=X \beta+Z u+S m+e E q
$$

(Equation 1) 
where: $y$ is the vector of dependent variables (W365, W450, W550, WGW365, WGW450, WGW550); $\beta$ is the vector of fixed effects; $u$ is the vector of random effects of animal genetic value; $m$ is the vector of random effects of maternal genetic value, and $e$ is the vector of random residual effect. Incidence matrices $X, Z$ and $S$ relate phenotype to $\beta, u$ and $m$ effects, respectively.

Heritability for total genetic merit, $\mathrm{h}_{\mathrm{t}}{ }_{\mathrm{t}}$ was obtained according to Willham (1972).

\section{RESULTS AND DISCUSSION}

Variance components and genetic parameters for postweaning weights are presented in Table 2. The direct genetic effect decreased with increase in age in the postweaning period. The same occurred with the maternal genetic effect, which was important even at 550 days of age in this breed. According to Robinson (1981), genetic maternal effects have a tendency to decrease with increase in age, but can persist during the postweaning period or for the whole life of the animal. Meyer et al. (1994) reported that the difference of maternal effects between breeds is often attributed to variations in total milk production. With the reduction of direct genetic effect, the proportion of environmental in relation to phenotypic variance $\left(\mathrm{e}^{2}\right)$ increased from 0.58 at 365 days to 0.69 at 550 days.

\begin{tabular}{|c|c|c|c|}
\hline Parameter & W365 & W450 & W550 \\
\hline \multicolumn{4}{|c|}{ Variance components } \\
\hline$\sigma_{a}^{2}$ & 412.72 & 487.04 & 374.01 \\
\hline$\sigma_{\mathrm{m}}^{\mathrm{a}}$ & 284.34 & 350.86 & 289.66 \\
\hline$\sigma_{\mathrm{a}, \mathrm{m}}$ & -82.56 & 0.91 & 46.29 \\
\hline$\sigma_{\mathrm{e}}^{2}$ & 831.54 & 1081.74 & 1568.17 \\
\hline$\sigma_{\mathrm{p}}^{2}$ & 1446.03 & 1919.86 & 2278.13 \\
\hline \multicolumn{4}{|c|}{ Genetic parameter } \\
\hline $\mathrm{h}^{2}{ }_{\mathrm{a}}$ & $0.29 \pm 0.061$ & $0.25 \pm 0.057$ & $0.16 \pm 0.060$ \\
\hline $\mathrm{h}^{2}{ }_{m}^{2}$ & $0.20 \pm 0.035$ & $0.18 \pm 0.035$ & $0.13 \pm 0.052$ \\
\hline $\mathrm{h}_{\mathrm{t}}^{2}$ & 0.30 & 0.35 & 0.26 \\
\hline$r_{a m}$ & $-0.24 \pm 0.137$ & $0.00 \pm 0.168$ & $0.14 \pm 0.313$ \\
\hline $\mathrm{e}^{2}$ & $0.58 \pm 0.049$ & $0.56 \pm 0.050$ & $0.69 \pm 0.065$ \\
\hline
\end{tabular}

The heritability estimated for W365 was larger than for other Bos taurus breeds $(0.23)$ described by Lôbo et al. (2000), but smaller than the general average in their review (0.33). In the review conducted by Koots et al. (1994), an average of 0.35 for this trait was reported, but they described estimates of 0.11 for maternal heritability, smaller than that observed in this study (0.20). Marques et al. (1999) described lower values for direct, maternal and total heritabilities of 0.17, 0.06 and 0.13, respectively, for the Simmental breed raised in Brazil, using a similar mathematical model for estimation of these parameters.

With regard to genetic parameters for weight at 365 and 450 days of age in the Nellore breed, Bittencourt et al. (2002) used a model that included direct and maternal genetic effect, without permanent environmental effect. These authors reported estimates for direct heritability of 0.28 and 0.35 for weight at 365 and 450 days, and 0.10 and 0.07 for maternal heritability at 
the same ages, respectively. In the present study, these coefficients were larger for these weights (Table 2). Arthur et al. (2001) described for weight at 400 days of age in the Angus breed a direct heritability of similar magnitude (0.27), but lower for maternal heritability (0.04). For weight at 550 days (W550), the heritability estimates were lower than those obtained at younger ages, and also lower than that reported in the literature, i.e., 0.31 as described by Lôbo et al. (2000). Eler et al. (1996) reported estimates of 0.30 for W550 for the Nellore breed.

Estimates of maternal heritability coefficients found in this study for the postweaning weights were higher than those normally described in the literature, indicating the great influence of the dam up to 18 months of age (550 days). Total heritability estimated for the three weight traits was largely influenced by the magnitude of the covariance between direct and maternal genetic effect. This correlation was negative for weight at 365 days, close to 0 at 450 days, and positive at 550 days, and thus, the coefficient of total heritability was highest for 450 days of age.

The genetic additive direct and maternal effects increased when the interval of time between the weights considered in the weight gain was longer, being more representative for the WGW550 than for WGW365 (Table 3). In the study reviewed by Meyer (1992), the direct additive heritability for weight gain in postweaning ranged from 0.26 to 0.37 , while the later review by Koots et al. (1994) showed a similar value of 0.29; those values were higher than these obtained in the present study.

\begin{tabular}{|c|c|c|c|}
\hline Parameter & WGW365 & WGW450 & WGW550 \\
\hline \multicolumn{4}{|c|}{ Variance components } \\
\hline$\sigma_{\mathrm{a}}^{2}$ & 97.87 & 195.07 & 274.67 \\
\hline$\sigma_{m}^{2}$ & 51.01 & 112.53 & 182.86 \\
\hline$\sigma_{\mathrm{a}, \mathrm{m}}$ & 6.09 & -6.66 & -141.43 \\
\hline$\sigma_{\mathrm{e}}^{2}$ & 599.92 & 861.21 & 1221.27 \\
\hline$\sigma_{p}^{c}$ & 748.90 & 1162.14 & 1537.37 \\
\hline \multicolumn{4}{|c|}{ Genetic parameters } \\
\hline $\mathrm{h}_{\mathrm{a}}^{2}$ & $0.12 \pm 0.043$ & $0.17 \pm 0.054$ & $0.18 \pm 0.075$ \\
\hline $\mathrm{h}^{2}{ }^{2}$ & $0.07 \pm 0.037$ & $0.10 \pm 0.042$ & $0.12 \pm 0.073$ \\
\hline $\mathrm{h}^{{ }^{2}{ }_{t}}$ & 0.18 & 0.21 & 0.10 \\
\hline $\mathrm{r}_{\mathrm{a}, \mathrm{m}}$ & $0.09 \pm 0.350$ & $-0.04 \pm 0.290$ & $-0.63 \pm 0.270$ \\
\hline $\begin{array}{c}\mathrm{e}^{\mathrm{a} m \mathrm{~m}} \\
\mathrm{e}^{2}\end{array}$ & $0.80 \pm 0.045$ & $0.74 \pm 0.054$ & $0.79 \pm 0.074$ \\
\hline
\end{tabular}

With an experimental herd of Braunvieh, Bennett and Gregory (1996), reported a substantial direct heritability of 0.48 for postweaning weight gain between 200 and 365 days of age. However, in studies of postweaning weight gain conducted in Angus and Hereford breeds, Wilson et al. (1986) described a direct heritability of 0.15 and 0.16 , for each breed, respectively. Both studies were carried out in the United States.

For maternal heritability in postweaning weight gain, the estimates described by Meyer (1992) were close to zero. Nevertheless, Koots et al. (1994) reported values as high as 0.24. We found intermediate coefficients of maternal heritability, when compared to the aforementioned reviews, which ranged from 0.07 to 0.12 . 
The direct heritability estimated for WGW450 (0.17) was slightly lower than the value of 0.20 reported by Cardoso et al. (2004) for weight gain between 205 and 410 days of age in the Angus breed, although these authors did not include the maternal effect. With regard to total heritability, a better response to selection would be expected for WGW450 than for WGW365 or WGW550. Nevertheless, total heritability was strongly influenced by the covariance between direct and maternal effects. The correlation between direct and maternal genetic effects was not very important for WGW365 and WGW450, but a substantial negative correlation $(-0.63)$ was observed for WGW550.

When studying weight gains between 12 and 18 months of age, it was possible to observe a large environmental influence on these traits (Table 4), possibly due to the diversity of environmental conditions provided to the animals in this period, thus hindering good responses to selection for these traits. Other authors also observed the great environmental influence in this phase, resulting in low coefficients of heritability (Mascioli et al., 2000; Paneto et al., 2002; Sarmento et al., 2003).

Table 4. Variance components and genetic parameters of weight gains (WG) from 365 to 550 days of age in Braunvieh cattle.

\begin{tabular}{|c|c|c|c|}
\hline Parameter & WG365550 & WG365450 & WG450550 \\
\hline \multicolumn{4}{|c|}{ Variance components } \\
\hline$\sigma_{a}^{2}$ & 111.21 & 47.05 & 26.51 \\
\hline$\sigma^{2}{ }_{e}^{a}$ & 779.48 & 308.25 & 498.96 \\
\hline$\sigma^{e}{ }_{p}^{e}$ & 890.69 & 355.30 & 525.47 \\
\hline \multicolumn{4}{|c|}{ Genetic parameters } \\
\hline $\mathrm{h}^{2}{ }_{\mathrm{a}}$ & $0.12 \pm 0.051$ & $0.13 \pm 0.047$ & $0.05 \pm 0.036$ \\
\hline$e^{2}$ & $0.88 \pm 0.051$ & $0.87 \pm 0.047$ & $0.95 \pm 0.036$ \\
\hline
\end{tabular}

For WG365550, the coefficient for direct heritability was estimated to be 0.12 . In the Canchim breed, Mascioli et al. (2000) reported a higher magnitude of heritability for the same trait $(0.20)$ with further decrease for the weight gain between 18 and 24 months $(0.13)$ and concluded that it produced better response to selection for weight gain in preweaning than postweaning. Sarmento et al. (2003), in a study with Nellore animals, reported a heritability of 0.21 for WG365550, and for this trait the authors found no maternal effects.

Few studies were found in the literature with regard to WG365450 and WG450550, probably due to the fact that weight at 450 days is not normally studied. In the Nellore breed, Paneto et al. (2002) observed for weight gain between 365 and 455 days and between 455 and 550 days, coefficients of heritability of 0.21 and 0.23 , respectively, values slightly higher than those obtained in our study. The low coefficient of heritability found for WG365450 (0.13) was even lower for WG450550 (0.05), thus demonstrating that with increasing age environmental effects on the performance of animals increase.

The genetic correlation was greater when the measurements were nearest (Table 5). The phenotypic correlation followed the behavior of genetic correlation, but with values generally smaller than the genetic correlation obtained between the same weights. This was also observed in the review by Lôbo et al. (2000). 


\begin{tabular}{lccc}
\multicolumn{4}{c}{ Table 5. Genetic correlation (above diagonal) and phenotypic correlation (below diagonal) for postweaning weights. } \\
\hline Trait & W365 & W450 & W550 \\
\hline W365 & - & $0.97 \pm 0.021$ & $0.89 \pm 0.069$ \\
W450 & 0.86 & - & $0.92 \pm 0.045$ \\
W550 & 0.79 & 0.89 & - \\
\hline
\end{tabular}

$\mathrm{W} 365, \mathrm{~W} 450, \mathrm{~W} 550=$ weight at 365,450 and 550 days of age, respectively.

High correlations were expected between those weights, because the weight at younger age is a component of weight at later age.

The genetic correlation was generally higher than phenotypic between weights and weight gains in postweaning (Table 6). In this study, the genetic correlation obtained between W205 and WG205365 (0.52) was lower than that reported by Bennett and Gregory (1996) in Braunvieh cattle (0.76) and by Mascioli et al. (2000) in Canchim cattle (0.73), but higher than that reported by Lôbo et al. (2000) of 0.22. For the correlation between W365 and WG205365, the value (0.76) was slightly higher than that reported by Lôbo et al. (2000) of 0.70 and Mascioli et al. (2000) of 0.74 . There are few studies in the literature that include the genetic correlation between $\mathrm{W} 450$ and weight gains.

Table 6. Genetic correlation $\left(\mathrm{r}_{\mathrm{g}}{ }_{\mathrm{g}}\right)$ and phenotypic correlation $\left(\mathrm{r}_{\mathrm{p}}{ }_{\mathrm{p}}\right)$ between weights and weight gains.
\begin{tabular}{lccc}
\hline Trait & $\begin{array}{c}\text { WGW365 } \\
\mathrm{r}_{\mathrm{g}}^{2} ; \mathrm{r}^{2}\end{array}$ & $\begin{array}{c}\text { WGW450 } \\
\mathrm{r}_{\mathrm{g}}{ }_{\mathrm{g}} ; \mathrm{r}_{\mathrm{p}}\end{array}$ & $\begin{array}{c}\text { WGW550 } \\
\mathrm{r}_{\mathrm{g}} ; \mathrm{r}_{\mathrm{p}}\end{array}$ \\
\hline W205 & $0.52 \pm 0.127 ; 0.07$ & $0.33 \pm 0.120 ; 0.11$ & $0.39 \pm 0.092 ; 0.16$ \\
W365 & $0.76 \pm 0.102 ; 0.76$ & $0.75 \pm 0.089 ; 0.68$ & $0.73 \pm 0.079 ; 0.62$ \\
W450 & $0.82 \pm 0.114 ; 0.73$ & $0.83 \pm 0.068 ; 0.86$ & $0.86 \pm 0.167 ; 0.78$ \\
W550 & $0.50 \pm 0.037 ; 0.63$ & $0.63 \pm 0.062 ; 0.77$ & $0.86 \pm 0.088 ; 0.89$ \\
\hline
\end{tabular}

For other abbreviations, see legend to Table 1.

The genetic correlation between the weight at 550 days and WG205365 was estimated as an intermediate value of 0.50 , lower than that described by Lôbo et al. (2000) who reported estimates of 0.78. A high value of correlation (0.86) was obtained between the W550 and WGW550; Lobo et al. (2000) reported a value of 0.61 for this same trait.

In the study of genetic correlations between weights and weight gains, Mascioli et al. (2000) concluded that there was high correlation between the weights of weaning to 18 months with weight gains between these ages in Canchim cattle.

In the present study, genetic correlations of intermediate and low magnitude were obtained between W205 and postweaning weight gains, indicating that selection for weaning weight did not necessarily lead to animals having high weight gain in postweaning. However, W365, W450 and W550 had the intermediate to high magnitude correlations with postweaning weight gain.

W450 was the trait that correlated most with postweaning weight gain. However, since W365 also showed important correlations albeit lower and considering the management adopted on the farms, it is possible to use indirect selection for postweaning weight gain from W450 or W365. In this type of selection, by the weight of the animal at a certain age, one should take into account the possibility of increasing the mature weight of the herd, which may not be desired, being detrimental to the performance of the population in the long term, and thus, further studies are needed to learn more about the growth curve in this breed. 


\section{CONCLUSIONS}

The coefficients of heritability observed for postweaning weights decreased with age, being higher at 365 days than to 450 or 550 days of age. Great dam influence was observed up to 18 months in this breed. The genetic correlations obtained in adjacent weights were higher than in measurements made with a greater time interval.

A greater environmental influence was found for weight gains between weaning and 550 days of age, and the coefficients of heritability were higher when the interval between measurements was longer. The magnitude of the environmental effects observed for the weight gains between 365 and 550 days was even greater, and thus, the expected genetic gain in the selection for these traits is not satisfactory. High genetic correlations between weights and weight gains were observed between weight gain and weight of the upper limit, and thus, the weight of the upper limit is a better indicator of weight gain in question.

Genetic correlations between weaning weight and weight gain in the postweaning period was of medium to low magnitude, and thus, in order to improve postweaning weight gain, the selection of animals for heavy weaning weight is not highly efficient, with better guidance to own weight gain or weight in older age.

\section{ACKNOWLEDGMENTS}

Research supported by FAPESP (Fundação de Amparo à Pesquisa do Estado de São Paulo), and the Nucleus of Braunvieh Breeders of Brazilian Breeders Association of Braunvieh and Brown Swiss Cattle.

\section{REFERENCES}

Arthur PF, Archer JA, Johnston DJ, Herd RM, et al. (2001). Genetic and phenotypic variance and covariance components for feed intake, feed efficiency, and other postweaning traits in Angus cattle. J. Anim. Sci. 79: 2805-2811.

Bennett GL and Gregory KE (1996). Genetic (co)variances among birth weight, 200-day weight, and postweaning gain in composites and parental breeds of beef cattle. J. Anim. Sci. 74: 2598-2611.

Bittencourt TCC, Rocha JCMC, Lôbo RB and Bezerra LF (2002). Variance components and breeding values for post weaning growth traits of Nellore cattle, from different statistical models. (Estimação de componentes de (co) variâncias e predição de DEP's para características de crescimento pós-desmama de bovinos da raça Nelore, usando diferentes modelos estatísticos). Arq. Bras. Med. Vet. Zootec. 54: 303-308.

Boldman KG, Kriese LA, Van Vleck LD and Kachman SD (1995). A Manual for Use of MTDFREML: a Set of Programs to Obtain Estimates of Variances and Covariances (DRAFT). USDA-ARS, Lincoln.

Cardoso FF, Cardellino RA and Campos LT (2004). (Co)Variance components and genetic parameters of post-weaning traits in Angus cattle. R. Bras. Zootec. 33: 313-319.

Corrêa MBB, Dionello NJL and Cardoso FF (2006). Estimation of genetic parameters and (co)variance components for preweaning productive traits in Devon Cattle in Rio Grande do Sul. R. Bras. Zootec. 35: 997-1004.

Cucco DC (2008). Estimativa de Parâmetros Genéticos para Características de Crescimento e Perímetro Escrotal na Raça Pardo Suíço Corte. Master's thesis, Faculdade de Zootecnia e Engenharia de Alimentos, Universidade de São Paulo, Pirassununga. Available at [http://www.teses.usp.br/teses/disponiveis/74/74131/tde-11032008-090556/ publico/5581102.pdf]. Accessed August 1, 2009.

Cucco DC, Ferraz JB, Pinto LF, Eler JP, et al. (2009). Genetic parameters for pre-weaning traits in Braunvieh cattle. Genet. Mol. Res. 8: 291-298.

Eler JP, Ferraz JBS and Silva PR (1996). Parâmetros genéticos para peso, avaliação visual e circunferência escrotal na raça Nelore, estimados por modelo animal. Arq. Bras. Med. Vet. Zootec. 48: 203-213.

Koots KR, Gibson JP, Smith C and Wilton JW (1994). Analyses of published genetic parameter estimates for beef 
production traits. 1. Heritability. Anim. Breed. Abst. 62: 309-338.

Lôbo RNB, Madalena FE and Vieira AR (2000). Avaliação genética de animais jovens, touros e matrizes: Sumário do PMGRN. Anim. Breed. Abst. 68: 433-462.

Marques LFA, Pereira JCC, Oliveira HN, Pereira CS, et al. (1999). Variance components and genetic parameters estimates for growth traits of Simmental cattle in Brazil. Arq. Bras. Med. Vet. Zootec. 51: 363-370.

Mascioli AS, El Faro L, Alencar MM, Fries LA, et al. (2000). Genetic and phenotypic parameters and principal components analyses for body weight gains in Canchim cattle. Rev. Bras. Zootec. 29: 1654-1660.

Meyer K (1992). Variance components due to direct and maternal effects for growth traits of Australian beef cattle. Liv. Prod. Sci. 31: 179-204.

Meyer K, Carrick MJ and Donnelly BJ (1994). Genetic parameters for milk production of Australian beef cows and weaning weight of their calves. J. Anim. Sci. 72: 1155-1165.

Paneto JCC, Lemos DC, Bezerra LAF, Martins Filho R, et al. (2002). Study of quantitative growth traits from 120 to 550 days of age in Nellore Cattle. R. Bras. Zootec. 31: 668-674.

Robinson OW (1981). The influence of maternal effects on the efficiency of selection: A review. Liv. Prod. Sci. 8: 121-137.

Sarmento JLR, Pimenta Filho EC, Ribeiro MN and Martins Filho R (2003). Genetic and environmental effects on Nellore Cattle growth in Paraíba. Rev. Bras. Zootec. 32: 325-330.

Siqueira RLPG, Oliveira JA, Lôbo RB, Bezerra LAF, et al. (2003). Additive genetic variability analysis in the growth characteristics of Nellore breed. Rev. Bras. Zootec. 32: 99-105.

Willham RL (1972). The role of maternal effects in animal breeding. 3. Biometrical aspects of maternal effects in animals. J. Anim. Sci. 35: 1288-1293.

Wilson DE, Berger PJ and Willham RL (1986). Estimates of beef growth trait variances and heritabilities determined from field records. J. Anim. Sci. 63: 386-394. 